\title{
GREEN SYNTHESIS OF SILVER NANOPARTICLES (AgNPS) USING HELVELLA LEUCOPUS PERS. AND THEIR ANTIMYCOTIC ACTIVITY AGAINST FUNGI CAUSING FUNGAL ROT OF APPLE
}

\author{
MEHRAJUD DIN TALIE*, ABDUL HAMID WANI, NUSRAT AHMAD, MOHD YAQUB BHAT, JOHN MOHD WAR
}

Department of Botany, Section of Mycology and Plant Pathology, University of Kashmir, Srinagar, Jammu and Kashmir, India. Email: danishmehraj143@gmail.com

Received: 21 January 2020, Revised and Accepted: 25 February 2020

\section{ABSTRACT}

Objectives: The main objective of the present study was to synthesize silver nanoparticles (AgNPs) by green approach using Helvella leucopus and to evaluate the antimycotic activity of synthesized AgNPs against fungi causing fungal rot of apple.

Methods: During the present study for green synthesis of AgNPs using H. leucopus, equal volumes of both mushroom extract (100 ml) and silver nitrate solution $(100 \mathrm{ml})$ were mixed and incubated at room temperature for the bioreduction process. These synthesized AgNPs were characterized by ultraviolet-visible spectroscopy, scanning electron microscopy, Fourier transmission infrared spectroscopy, and X-ray diffraction analysis. Furthermore, these synthesized AgNPs were evaluated for their antimycotic activity by spore germination method and agar well diffusion assay against different tested fungi.

Results: The results revealed that strong plasmon absorbance band was observed at $420 \mathrm{~nm}$ which confirms the synthesis of AgNPs using H. leucopus. The synthesized AgNPs were spherical in aggregated form with size ranging from 80 to $100 \mathrm{~nm}$. Furthermore, different concentrations of synthesized AgNPs caused significant inhibition in spore germination and reduction in zone of inhibition of tested fungal pathogens. The highest inhibition in spore germination by AgNPs at highest concentrations was observed against Penicillium chrysogenum followed by Aspergillus niger and Alternaria alternata, respectively. Similarly, the synthesized AgNPs at highest concentrations showed maximum zone of inhibition against $P$. chrysogenum followed by A. niger and A. alternata, respectively.

Conclusion: It is concluded from the present study that synthesized AgNPs have good potential to be used as antifungal agents against many fungal plant pathogens. The synthesized AgNPs using mushroom fungi also have potential for the development of nanofungicides against fungal pathogens but after proper investigation.

Keywords: Silver nanoparticles, H. leucopus, Fungal rot pathogens, Characterization, Antimycotic activity.

(c) 2020 The Authors. Published by Innovare Academic Sciences Pvt Ltd. This is an open access article under the CC BY license (http://creativecommons. org/licenses/by/4. 0/) DOI: http://dx.doi.org/10.22159/ajpcr.2020.v13i4.37024

\section{INTRODUCTION}

Nanotechnology, a multidisciplinary and emerging field of science, covers diverse area of research and technology in physics, chemistry, and biology [1]. Physical synthesis of nanoparticle gives low yield [2] while as chemical methods are toxic to the environment. However, biological synthesis of nanoparticles is advantageous than physical and chemical methods because of rapid synthesis, better control over size and shape characteristics, less toxicity, cost-effectiveness, and eco-friendly approach $[3,4]$. Various plants, bacteria, fungi, algae, and viruses have been used for biological synthesis of nanoparticles [5]. However, the most widely accepted approach is using bacteria and fungi because they are easy to manipulate and handle [6].

Several methods have been applied for the management of fungal and bacterial pathogens but these have some limitations [7-10]. However, synthesized nanoparticles have great potential to be used as antifungal and antibacterial agents because they are considered as alternate, cost effective, and eco-friendly management strategy for the control of pathogenic microbes $[4,11,12]$.

Various mushrooms, namely, Volvariella volvacea, Pleurotus sajorcaju, Pleurotus florida, Ganoderma lucidum, Ganoderma applanatum, Agaricus bisporus, Fomes fomentarius, Helvella sp., and Microporus xanthopus have been assessed for the synthesis of silver and other nanomaterials [13-17]. Silver nanoparticles (AgNPs) have become increasingly popular as antifungal, antibacterial, antioxidant, and antiinflammatory agents $[18,19]$.
Considering the present environmental scenario and other safety measures, there is widespread interest in developing cost effective, benign, and eco-friendly approach for the synthesis of nanoparticles [20]. Therefore, the present study entitled "Green synthesis of AgNPs using Helvella leucopus Pers. and their antimycotic activity against fungi causing fungal rot of Apple" was carried out $1^{\text {st }}$ time from Kashmir, India. These synthesized AgNPs were characterized and evaluated for their antifungal activity against fungal rot pathogens such as Penicillium chrysogenum, Aspergillus niger, and Alternaria alternata with respect to spore germination and reduction in zone of inhibition.

\section{METHODS}

\section{Sample collection}

During the present study, H. leucopus was collected from different localities of Northern Kashmir such as Sopore, Pattan, Tangmarg, and Sumbal Sonawari. The mushroom was then identified based on morphological, reproductive, and other characteristics [21,22]. This mushroom was cleaned and then dried at room temperature for the synthesis of AgNPs. The identified mushroom was found positive for AgNPs production and gives positive peak while performing spectrophotometric analysis.

\section{Biosynthesis of AgNPs}

About 5-20 g of dried mushroom specimen were taken and washed thoroughly with distilled water to free from the mud and dust adhering. The cleaned mushroom after complete redrying was ground to fine powder with the help of grinder. The powdered sample was suspended 
in $150 \mathrm{ml}$ of deionized water and heated for 5-10 min. The extract was cooled at room temperature, then filtered 2 times and stored at $4^{\circ} \mathrm{C}$ for further use. During the present study, equal volumes of both mushroom extract $(100 \mathrm{ml})$ and silver nitrate $\left(\mathrm{AgNO}_{3}\right)$ solution $(100 \mathrm{ml})$ were mixed and incubated at room temperature for the bioreduction process. Simultaneously, H. leucopus extract was taken as positive control while as $\mathrm{AgNO}_{3}$ solution acts as negative control [23].

\section{Characterization of AgNPs}

Following techniques were employed for the characterization of synthesized AgNPs.

\section{Ultraviolet (UV)-visible spectroscopy}

UV-visible spectroscopic analysis was performed on UV-visible absorption spectrophotometer (UV-119 Systronics) between the wavelengths of 300 and $700 \mathrm{~nm}$. The process of reaction between $\mathrm{AgNO}_{3}$ ions and $H$. leucopus extract was assessed by UV-visible absorption spectra of AgNPs in aqueous solution.

\section{Scanning electron microscopy (SEM)}

SEM analysis was used to measure the size of AgNPs. For SEM, the AgNPs synthesized using H. leucopus were allowed to complete dryness and grounded well to superior quality powder.

\section{Fourier transmission infrared (FTIR) spectroscopy}

The resultant suspension of AgNPs synthesized using H. leucopus was initially centrifuged at $3000 \mathrm{rpm}$ for $15 \mathrm{~min}$, to remove the unwanted impurities. The supernatant was centrifuged 3 times up to $10,000 \mathrm{rpm}$ for $15 \mathrm{~min}$. Pellets obtained were washed with distilled water to get the pure AgNPs and were completely air-dried at room temperature. The collected powdered material of synthesized AgNPs was taken for FTIR spectroscopy analysis using broker (Alpha 200486) instrument in the range of $450-4500 \mathrm{~cm}^{-1}$.

\section{$X$-ray diffraction (XRD) analysis}

After the reduction process, the suspension obtained was cleaned and purified by centrifugation at 5000-10,000 rpm for $20 \mathrm{~min}$. After air-drying of the purified AgNPs, the structure as well as composition were examined by XRD analysis in the range of 20-90. However, to verify the UV-visible spectral results, the powdered sample of synthesized AgNPs was analyzed by XRD pattern to confirm its crystalline nature.

\section{Antifungal assay}

\section{Test organisms}

The pathogenic fungi such as P. chrysogenum Thom (1910), A. niger Van Tieghem (1867), and A. alternata (Fr.) Keissl. (1912) used during the present study were obtained from Plant Pathology and Mycology, Department of Botany, University of Kashmir, Hazratbal, Srinagar (190006)

\section{Spore germination method}

The evaluation of antimycotic activity of synthesized AgNPs was assessed by spore germination method against different test fungi. Different concentrations, namely, $10 \mathrm{mg} / \mathrm{ml}, 15 \mathrm{mg} / \mathrm{ml}$, and $20 \mathrm{mg} / \mathrm{ml}$ were prepared from the dried and purified material of synthesized AgNPs. Furthermore, spore suspension of each test fungus was prepared in sterilized distilled water containing $1 \times 10^{3}$ conidia $/ \mathrm{ml}$. A drop of about $0.01 \mathrm{ml}$ from a particular test fungus was placed on cavity slide. Equal volume of the respective concentration of synthesized AgNPs was also placed on the same cavity slide and was incubated for $25 \pm 2{ }^{\circ} \mathrm{C}$ in a soaked blotting chamber to maintain required humidity. For control, a drop of spore suspension as well as respective test fungi was taken on cavity slide. Each treatment was maintained in the replicates of three including standard. The slides after incubation were then examined on stereoscopic microscope. The percentage of germination of spores was calculated by the formula [24].

\author{
Percent spore germination $(\%)=\frac{\text { No. of spores germinated }}{\text { Total No. of spores examined }} \times 100$ \\ Inhibition of spore germination $(\%)=\frac{\mathrm{Gc}-\mathrm{Gt}}{\mathrm{Gc}} \times 100$
}

Where, Gc and Gt represent the average number of germinated conidia in control and treated plates, respectively.

\section{Agar well diffusion method}

The antimycotic activity of synthesized AgNPs was evaluated against rot causing fungi by agar well diffusion assay as adopted by Wiegand et al. [25]. Different concentrations, namely, $10 \mathrm{mg} / \mathrm{ml}, 15 \mathrm{mg} / \mathrm{ml}$, and $20 \mathrm{mg} / \mathrm{ml}$ were prepared in sterilized distilled water. Nystatin $50 \mathrm{ul} /$ disc was used as standard while as distilled water was taken as negative control. About $0.02 \mathrm{ml}$ spore suspension of each test fungus was inoculated in $20 \mathrm{ml}$ of molten Sabouraud dextrose agar medium in culture tubes. The culture tubes after proper homogenization were poured into $90 \mathrm{~mm}$ Petri plates. These cultures were allowed to solidify under aseptic conditions in laminar airflow chamber. With the help of standard, $5 \mathrm{~mm}$ cork borer wells were prepared in solidified media. During the present study, the efficacy of different concentrations of synthesized AgNPs against different test fungi was assessed and compared with the positive control. The culture plates were sealed with cello tape and incubated at $25 \pm 2{ }^{\circ} \mathrm{C}$ for $48 \mathrm{~h}$. The antimycotic activity was determined by measuring the zone of inhibition [26].

\section{RESULTS}

Characterization of synthesized AgNPs using H. leucopus

Synthesized AgNPs using H. leucopus were characterized by the following techniques given below:

\section{UV-visible spectroscopy}

The preliminary indication of the synthesis of AgNPs using H. leucopus extract was confirmed by the color change from yellow to dark brown within 24 h (Fig. 1).

The reaction between $\mathrm{AgNO}_{3}$ solution and mushroom extract was assessed by UV-visible spectroscopic analysis between the wavelengths of 300 and $700 \mathrm{~nm}$. The strong plasmon absorbance band was observed at 420$450 \mathrm{~nm}$ (Fig. 2) which confirms the synthesis of AgNPs using H. leucopus.

\section{SEM analysis}

It was revealed from the results (Fig. 3) that synthesized AgNPs were spherical in aggregated form. The size of synthesized AgNPs ranges from 80 to $100 \mathrm{~nm}$.

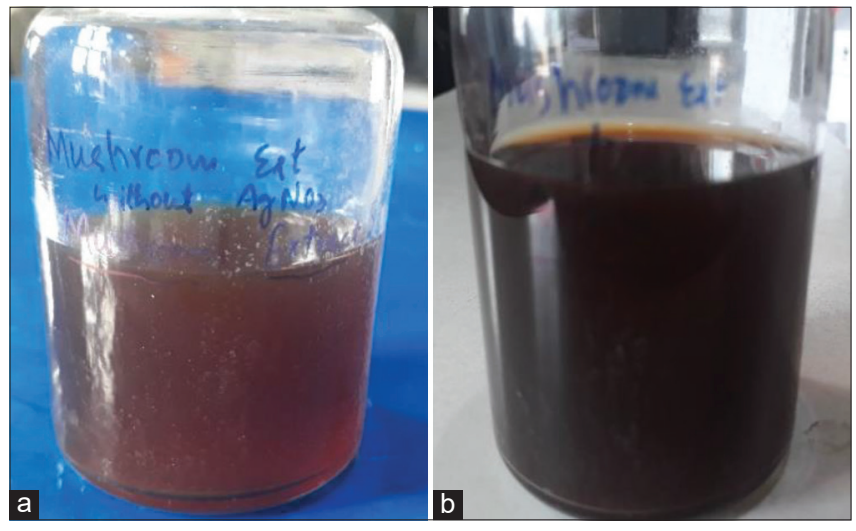

Fig. 1: Mushroom extract before and after the addition of silver nitrate $\left(\mathrm{AgNO}_{3}\right.$ ) solution (a) Mushroom extract before the addition of $\mathrm{AgNO}_{3}$, (b) mushroom extract after the addition of AgNO $_{3}$ 


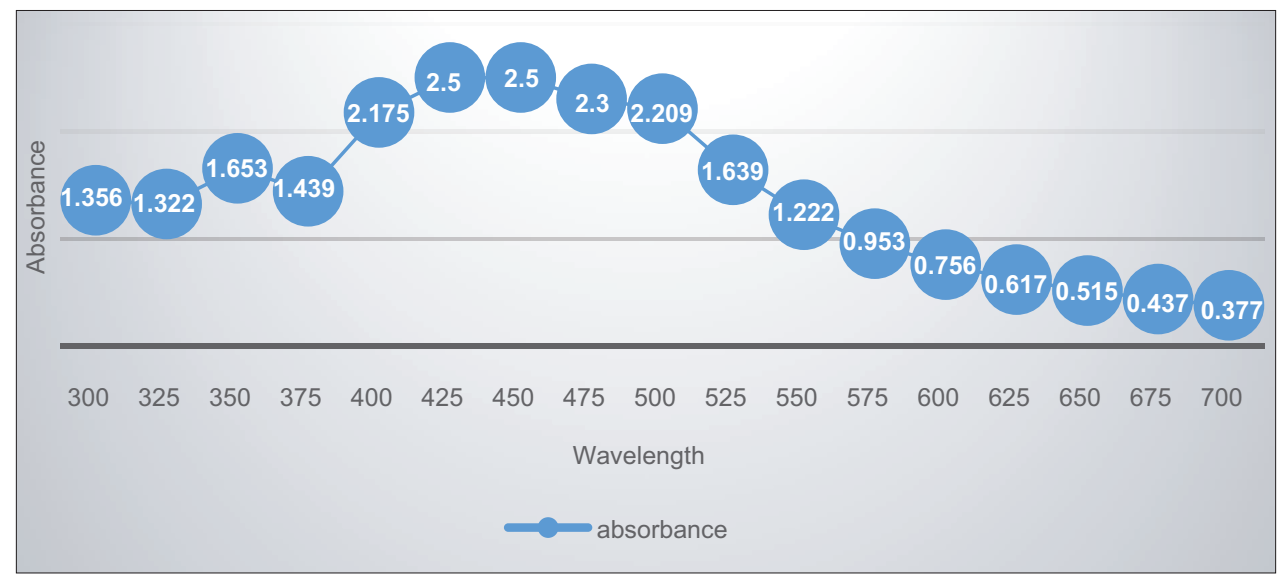

Fig. 2: Ultraviolet-visible spectroscopy of synthesized silver nanoparticles from Helvella leucopus

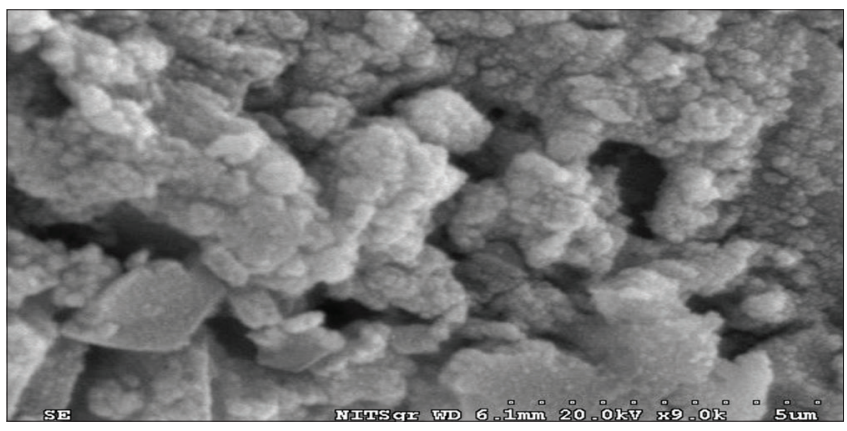

Fig. 3: Scanning electron microscopic micrograph of silver nanoparticles biosynthesized from $\mathrm{H}$. leucopus

\section{FTIR spectroscopy}

It was observed from the FTIR spectroscopy measurements (Fig. 4) that synthesized AgNPs absorb strongly at 3452.06, 2937.59, 2851.96, $2370.87,2345.48,1637.25,1384.41,1105.42$, and $407-496 \mathrm{~cm}^{-1}$. However, the absorption band of 3421.14 is associated to $\mathrm{N}-\mathrm{H}$ amine stretch and 2861.95-2937.69 absorption bands correspond to -OH of carboxylic acid. Likewise, the absorption band observed at $1384.41 \mathrm{~cm}^{-1}$ is in accordance with the C-N stretching vibrations of the aromatic amines while as 1637.25 absorption band is associated with unsaturated nitrogen compounds $\mathrm{O}-\mathrm{NO}_{2}$, nitrate, respectively.

Furthermore, the IR spectra show the bands which clarify the presence of N-H amine linkages, $\mathrm{O}-\mathrm{H}$ of carboxylic acid, C-N linkages of aromatic amines, and $\mathrm{O}-\mathrm{NO}_{2}$ unsaturated nitrogen compounds that may be present in the AgNPs as stabilizing caps along with the proteins and amino acid residues.

\section{XRD analysis}

It was revealed from the XRD measurements (Fig. 5) that synthesized AgNPs showed peaks in the whole spectrum ranging from 20 to 90 . The data obtained during the present study were matched with inorganic crystal structure database and international center for diffraction data using PDXL-2 software. While comparing the results of XRD spectrum obtained during present study with the standard, it was proved that these synthesized AgNPs were in the form of nanocrystal.

\section{Antifungal assay}

Effect of different concentrations of AgNPs on the spore germination of some test fungi

It was observed from the results (Table 1) that significant spore germination inhibition of all the test fungi was brought about at different concentrations of AgNPs. The highest concentrations of synthesized AgNPs caused maximum spore germination inhibition against $P$. chrysogenum (83.21\%) followed by A. niger (77.32\%) and A. alternata $(69.10 \%)$, respectively. However, lower concentrations of synthesized AgNPs also caused inhibition in spore germination against all the test fungal pathogens but to lesser extent.

\section{Agar well diffusion method}

The evaluation of antimycotic activity of different concentrations of synthesized AgNPs against P. chrysogenum, Aspergillus niger, and A. alternata was determined by measuring the zone of inhibition. It was revealed from the results (Table 2 and Fig. 6) that all the concentrations of synthesized AgNPs showed significant zone of inhibition. However, the highest concentrations of synthesized AgNPs brought about maximum zone of inhibition against $P$. chrysogenum $(24.00 \pm 1.00 \mathrm{~mm})$ followed by Aspergillus nigar $(20.33 \pm 0.57 \mathrm{~mm})$ and A. alternata $(19.33 \pm 1.54 \mathrm{~mm})$, respectively. Furthermore, the lowest concentrations of synthesized AgNPs also bring about non-specific reduction in zone of inhibition against all the test fungal strains.

\section{DISCUSSION}

In the present study, AgNPs were biosynthesized using mushroom fungi, $H$. leucopus and such studies have been carried out for the $1^{\text {st }}$ time in Kashmir, India. Likewise, in the present study, a strong plasmon absorbance band was observed at $420-450 \mathrm{~nm}$ which is in accordance with the work of Narasimha et al. [23]. Similar plasmon resonance peak was observed at $420 \mathrm{~nm}$ in case of AgNPs biosynthesized from A. bisporus by Haq et al. and Sudhakar et al. [17,27]. It has also been found in different studies that green synthesis of nanoparticles offers a simple, clean, nontoxic, and environmental-friendly approach of synthesizing nanoparticles with a wide range of morphological and physiochemical properties $[3,28]$.

After characterization of synthesized AgNPs using different techniques revealed that synthesized AgNPs were spherical in aggregated form with their size ranging from 80 to $100 \mathrm{~nm}$. Similar techniques were also used for characterization of other biosynthesized nanoparticles by different workers [28-31]. Furthermore, it was revealed from the results that synthesized AgNPs at different concentrations brought about significant spore germination inhibition and reduction in zone of inhibition against all the tested fungal rot pathogens indicating their antimycotic activity. In a similar study, Rajeshkumar et al. [32] reported antifungal activity of synthesized AgNPs against A. niger, Aspergillus fumigatus, Aspergillus flavus, Fusarium sp., and Candida albicans. Pulit et al. [33] also studied the antimycotic activity of synthesized AgNPs against $A$. niger and Cladosporium cladosporioides and also reported that these nanoparticles have potent biocidal activities even at lower concentrations as were found in the present study. The antifungal and antimicrobial activities of AgNPs synthesized from A. bisporus and Tricholoma crassum were also reported to be maximum at the highest concentrations followed by lower concentrations as were confirmed in the present investigation $[17,34]$. 
Table 1: Effect of AgNPs on spore germination \% and spore inhibition $\%$ against different fungi

\begin{tabular}{|c|c|c|c|c|}
\hline \multirow[t]{2}{*}{ Fungal pathogens } & \multicolumn{4}{|c|}{ Spore germination $\%$} \\
\hline & $10 \mathrm{mg} / \mathrm{ml}$ & $15 \mathrm{mg} / \mathrm{ml}$ & $20 \mathrm{mg} / \mathrm{ml}$ & Standard \\
\hline Penicillium chrysogenum & $27.40 \pm 0.57(57.38)$ & $18.52 \pm 0.57(69.00)$ & $9.04 \pm 0.58(83.21)$ & $55.25 \pm 1.00$ \\
\hline Alternaria alternata & $60.00 \pm 1.00(19.81)$ & $42.83 \pm 0.58(39.94)$ & $25.00 \pm 2.00(69.10)$ & $76.90 \pm 1.54$ \\
\hline
\end{tabular}

Table 2: Zone of inhibition by AgNPs against different test fungi

\begin{tabular}{|c|c|c|c|c|}
\hline \multirow[t]{2}{*}{ Fungal pathogens } & \multicolumn{4}{|c|}{ Zone of inhibition } \\
\hline & $10 \mathrm{mg} / \mathrm{ml}$ & $15 \mathrm{mg} / \mathrm{ml}$ & $20 \mathrm{mg} / \mathrm{ml}$ & Standard \\
\hline Penicillium chrysogenum & $16.33 \pm 1.52$ & $21.00 \pm 1.00$ & $24.00 \pm 1.00$ & $27.33 \pm 2.51$ \\
\hline Aspergillus niger & $13.00 \pm 1.00$ & $16.67 \pm 1.52$ & $20.33 \pm 0.57$ & $23.00 \pm 2.00$ \\
\hline Alternaria alternata & $13.33 \pm 0.57$ & $15.67 \pm 0.57$ & $19.33 \pm 1.54$ & $24.67 \pm 0.57$ \\
\hline
\end{tabular}

Values are represented as mean \pm SD. AgNPs: Silver nanoparticles

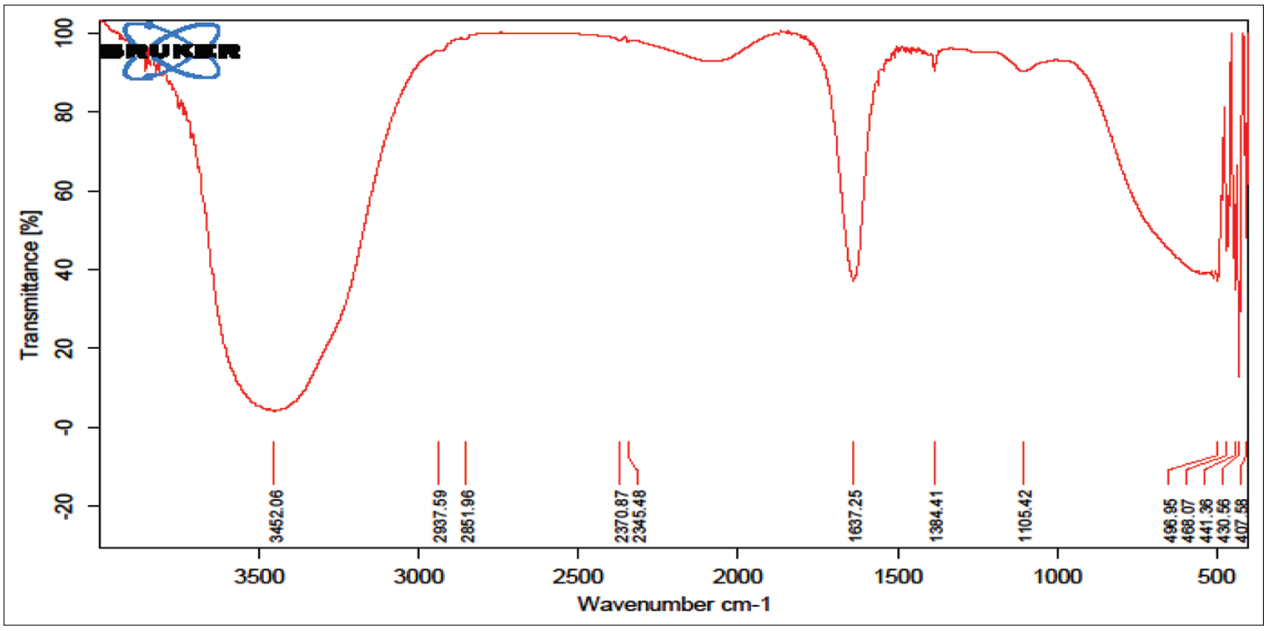

Fig. 4: Fourier transmission infrared spectra of silver nanoparticles biosynthesized from Helvella leucopus

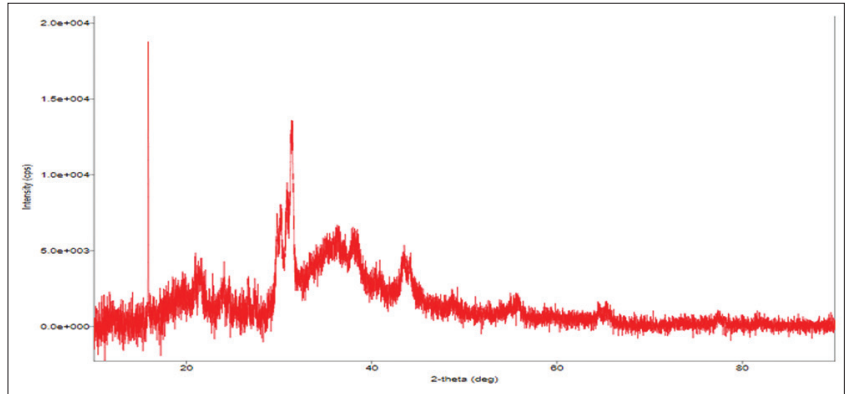

Fig. 5: X-ray diffraction spectrum of silver nanoparticles biosynthesized from $\mathrm{H}$. leucopus
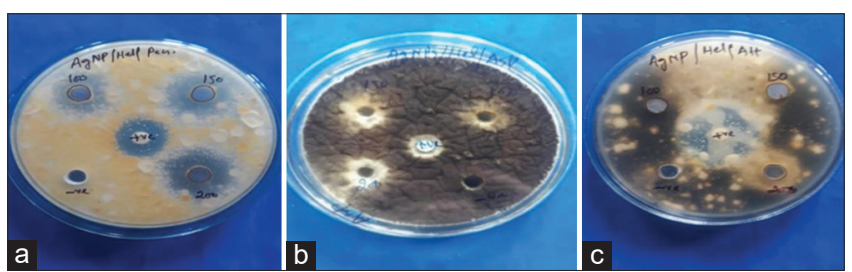

Fig. 6: Zone of inhibition by different concentrations of silver nanoparticles against (a) Penicillium chrysogenum, (b) Aspergillus niger, (c) Alternaria alternata

\section{CONCLUSION}

It is concluded from the present study that AgNPs have good potential to be used as antifungal agents against many fungal plant pathogens and controlling plant diseases caused by different fungal pathogens. The successful synthesis of AgNPs by active reduction of silver ions using $H$. leucopus extract as bioreductants can be developed an imperative new green technology solution, where mushrooms could be used actively for metal nanoparticles synthesis. The potential antimycotic activity against rot causing fungi will be boon for the apple growers and food industry to use such metal nanoparticles to reduce the contamination of fruits, vegetables, and food stuffs and also for their long time storage and preservation. The major complication of apple growers and food industry such as rotting, food contamination, and spoilage by fungi now can be resolved with continuous effort of using nanoparticles after proper investigation of their antifungal activity.

\section{ACKNOWLEDGMENT}

The authors are grateful to the Head, Department of Botany, University of Kashmir and Electron Microscopy Centre, Department of Physics, Faculty of Science, National Institute of Technology, Srinagar, for providing necessary help and facilities during the course of the study. The first author is also thankful to Council of Scientific and Industrial Research (CSIR), New Delhi, for providing NET-JRF fellowship. 


\section{AUTHORS' CONTRIBUTIONS}

The first and second authors conducted the experimental work while as the third and fourth authors helped in writing of manuscript. The last author helped in conducting antimycotic assays.

\section{CONFLICTS OF INTEREST}

On behalf of all authors, the corresponding author states that there are no conflicts of interest with regard to the preparation or publication of this manuscript.

\section{AUTHORS' FUNDING}

The first author is thankful to CSIR, New Delhi, for providing NET-JRF fellowship.

\section{REFERENCES}

1. Vuk U. Nanomaterials and nanotechnologies: Approaching the crest of this big wave. Curr Nanosci 2008;4:119-29.

2. Malik MA, Brien PO, Revaprasadu NA. Simple route to the synthesis of core/shell nanoparticles of chalcogenides. Chem Mater 2002;14:2004-10.

3. Shah M, Fawcett D, Sharma S, Tripathy SK, Poinern GE. Green synthesis of metallic nanoparticles via biological entities. Materials 2015;8:7278-308

4. Parveen S, Wani AH, Shah MA, Devi HS, Bhat MY, Koka JA. Preparation, characterization and antifungal activity of iron oxide nanoparticles. Microb Pathog 2018;115:287-92.

5. Thakkar KN, Mhatre SS, Parikh RY. Biological synthesis of metallic nanoparticles. Nanomedicine 2010;6:257-62.

6. Parikh RY, Singh S, Prasad BL, Patole MS, Sastry M, Shouche YS. Extracellular synthesis of crystalline silver nanoparticles and molecular evidence of silver resistance from Morganella sp. towards understanding biochemical synthesis mechanism. Chembiochem 2008;9:1415-22.

7. Griffiths E. Iatrogenic plant diseases. Ann Revis Phytopathol 1981;19:69-82.

8. Spotts RA, Cervantes LA. Population, pathogenicity and benomyl resistance of Botrytis spp. Penicillium spp. and Mucor piriformis in packinghouses. Plant Dis 1986;70:106-8.

9. Parveen S, Wani AH, Bhat MY, Pala SA, Ganie AA. Biology and management of Aspergillus Niger Van Tiegh. Causing black mold rot of pear (Pyrus communis L.) in Kashmir valley India. Int J Adv Res 2014:2:24-34

10. Abdullah Q, Mahmoud A, Al-Harethi A. Isolation and identification of fungal postharvest rot of some fruits in Yemen PSM. Microbiology 2016;1:36-44.

11. Raghupati RK, Koodali RT, Manna AC. Size-dependent bacterial growth inhibition and mechanism of antibacterial activity of zinc oxide nanoparticles. Langmuir 2011;27:4020-8

12. Kim SW, Jung JH, Lamsal K, Kim YS, Min JS, Lee YS. Antifungal effects of silver nanoparticles (AgNPs) against various plant pathogenic fungi. Mycobiology 2012;40:53-8.

13. Philip D. Biosynthesis of $\mathrm{Au}, \mathrm{Ag}$ and $\mathrm{Au}-\mathrm{Ag}$ nanoparticles using edible mushroom extract. Spectrochem Acta A Mol Biomol Spectrosc 2009;73:374-81.

14. Nithya R, Ragunathan R. Synthesis of silver nanoparticle using Pleurotus sajor caju and its antimicrobial study. Dig J Nanomater Biostruct 2009;4:623-9.

15. Karwa A, Gaikwad S, Rai M. Mycosynthesis of silver nanoparticles using lingzhi or reishi medicinal mushroom Ganoderma lucidum (W. Curt. Fr) Karst and their role as antimicrobials and antibiotic enhancers. Int J Med Mushrooms 2011;13:483-91.

16. Balahanmugam P, Santhosh S, Giyaullah H, Balakumaran MD, Kalaichelvan PT. Mycosynthesis, characterisation and antibacterial activity of silver nanoparticles from Microsporus xanthopus. A macro mushroom. Int J Innov Res Sci Eng Technol 2013;2:6262-70.

17. Haq M, Rathod V, Shivraj N, Singh D, Yasin M, Singh AK. Silver nanoparticles from mushroom Agricus bisporus and their activity against multi drug resistant strains of Klebsiella spp. Pseudomonas sp. and Acinetobacter sp. Int J Nat Prod Res 2015;5:20-6.

18. Tian J, Wong KK, Ho CM, Lok CN, Yu WY, Che CM, et al. Topical delivery of silver nanoparticles promotes wound healing. ChemMedChem 2007;2:129-36.

19. Stensberg MC, Wei Q, Mclamore ES, Porterfield DM, Wei A, Sepulveda MS. Toxicological studies on silver nanoparticles: Challenges and opportunities in assessment, monitoring and imaging. Nanomedicine 2011;6:879-98

20. Kulkarni N, Maddapur U. Biosynthesis of metal nanoparticles. A review. J Nanotechnol 2014;2014:1-8.

21. Kumar A, Bhatt RP, Lakhanpal TN. In: Singh B, Singh MP, editors. The Amanitaceae of India. Dheradun, India: Bishen Singh Mahendra Pal Singh; 1990

22. Atri NS, Kaur A, Kaur H. Wild mushrooms collection and identification. Mushroom Res 2003;14:56-9.

23. Narasimha G, Praveen BK, Mallikarjuna KB, Raju DP. Mushrooms (Agaricus bisporus) mediated biosynthesis of sliver nanoparticles. Characterization and their antimicrobial activity. Int $\mathrm{J}$ Nano Dim 2011:2:29-36

24. Kiraly Z, Klement Z, Solymosy F, Voros J. Methods in Plant Pathology with Special Reference to Breeding for Resistance. New York: Elsevier Publishing Company; 1974.

25. Wiegand I, Hilpert K, Hancock RE. Agar and broth dilution methods to determine the minimal inhibitory concentration (MIC) of antimicrobial substances. Nat Protoc 2008;3:163-75.

26. Norrel SA, Messley KE. Microbiology Laboratory Manual Principles and Applications. New Jersey: Prentice Hall Upper Saddle River; 1997. p. 85-90.

27. Sudhakar T, Nanda A, Babu SG, Janani S, Evans MD, Markose TK. Synthesis of silver nanoparticles from edible mushroom and its antimicrobial activity against human pathogens. Int J Pharm Tech Res 2014;5:1718-23.

28. Patil S, Sivaraj R, Rajiv P, Venckatesh R, Seenivasan R. Green synthesis of silver nanoparticle from leaf extract of Aegle marmelos and evaluation of its antibacterial activity. Int J Pharm Pharm Sci 2015;7:169-73.

29. Murugesa S, Bhuvaneswari S, Sivamurugan V. Green synthesis, characterization of silver nanoparticles of a marine red alga Spyridia fusiformis and their antibacterial activity. Int J Pharm Pharm Sci 2017:9:192-7.

30. Janakiraman M. Protective efficacy of silver nanoparticles synthesized from silymarin on cisplatin induced renal oxidative stress in albino rat. Int J Appl Pharm 2018;10:110-6.

31. Chandrappa CP, Chandrasekar N, Govindappa M, Shanbhag C, Singh UK, Masarghal J. Antibacterial activity of synthesized silver nanoparticles by Simarouba glauca against pathogenic Bacteria. Int J Curr Pharm Res 2017;9:19-22.

32. Rajeshkumar S, Malarkodi C, Kumar VS. Synthesis and characterization of silver nanoparticles from marine brown seaweed and its antifungal efficiency against clinical fungal pathogens. Asian J Pharm Clin Res 2017; 10:190-3.

33. Pulit J, Banach M, Szczyglowska R, Bryk M. Nanosilver against fungi. Silver nanoparticles as an effective biocidal factor. Acta Biochim Pol 2013;60:795-8.

34. Ray S, Sarkar S, Kundu S. Extracellular biosynthesis of silver nanoparticles using the mycorrhizal mushroom Tricholoma crassum (Berk.) Sacc: Its antimicrobial activity against pathogenic Bacteria and fungus, including multidrug resistant plant and human bacteria. Dig J Nanomater Bios 2011;6:1289-99. 